\title{
Smart disaster prediction application using flood risk analytics towards sustainable climate action
}

\author{
Michael M. Orozco*, and Jonathan M. Caballero \\ Technological Institute of the Philippines, Manila, Philippines
}

\begin{abstract}
Disaster prediction devices for early warning system are used by many countries for disaster awareness. This study developed smart disaster prediction application using microcontrollers and sensors to analyze the river water level for flood using flood risk analytics. Specifically, it monitors the river water level, water pressure and rainfall using microcontroller, applying statistical modeling algorithms for river flood prediction, and monitor flood in a web-based system with SMS notification and alarm to the community as an early warning. The researchers used the system development method to measure the prototype feasibility study. The researchers applied the statistical modeling algorithm as the data can be observed from time to time or on a daily basis for the predictive analytics. Based on the 7-days observation result, rainfall resulted in precipitation average of $10.96 \mathrm{~mm}$, water pressure with an average of 40.92 pound per square inch (psi) and water level averaged $138.78 \mathrm{~cm}$. The tropical depression during the 7 days' observation reflected the average data result from the sensors as the target of the study. The result of the prototype device used the City Disaster Risk and Reduction management office (CDRRMO) as history logs for a flood risk and it was proven accurate which makes a good use for disaster prediction.
\end{abstract}

\section{Introduction}

Flash flood becomes one of the major problem in a natural disaster that can cause damages to property that may affect human living as well. Based on the study of Tingsanchali (2012), flood impact is one of the most significant disasters in the world. More than half of global flood damages occur in Asia. Causes of floods are due to natural factors such as heavy rainfall, high floods and high tides, etc. Problems become more critical due to more severe and frequent flooding likely caused by climate change. Flood loss prevention and mitigation includes structural flood control measures and non-structural measures such as flood forecasting and warning, flood hazard and risk management [1].

Lagmay et al. (2017) stated that the project NOAH (Nationwide Operational Assessment of Hazards) in 2012 to raise the Filipinos' awareness of natural hazards. The Philippine Government launched this responsive program for disaster prediction specifically for government warning agencies to be able to provide a $6 \mathrm{hr}$. lead-time

* Corresponding author: Orozco.michael@uphsl.edu.ph 
warning to vulnerable communities against impending floods and to use advanced technology to enhance current geo-hazard vulnerability maps. To disseminate such critical information, a Web-GIS (Geographic Info. System) tool is used for the flood-prone hazard areas [2].

As of nowadays, many flood early warning systems are created to promote community awareness in a flood disaster. One of the related study by Krzhizhanovskaya et al. (2011) presented a prototype of the flood early warning system (EWS) developed within the UrbanFlood FP7 project. The system monitors sensor networks installed in flood defense, detects sensor signal abnormalities, calculates dike failure probability, and simulates possible scenarios of dike breaching and flood propagation [3].

Many flood monitoring and disaster prediction devices nowadays are used by many countries for disaster awareness. Disaster prediction devices may solve the difficulty in gathering information about the flood risk using data parameters that can be used.

This study developed smart disaster prediction application using flood risk analytics towards sustainable climate action. Specifically, it aims to monitor the river water level, water pressure and rainfall using Raspberry $\mathrm{Pi}$ microcontroller and sensors, design a notification management system for community flood warning, apply statistical modeling algorithms for river flood prediction and flood risk analytics, and deploy the flood monitoring in a web-based system. This will help for accurate disaster forecast based on the parameters used in thr study to predict possible flood that will affect the community.

The study encompassed the monitoring of the flood prone area in Biñan Laguna. Using the Internet of things with sensor technology to monitor the flood risk, the study will focus on the following areas. First, the river water level is included since the disaster risk office uses four (4) water alert levels. Second, rain is also included wherein the study will measure the precipitation of the rainfall. Third, the water pressure as the new contribution in the study wherein it will measure the water pressure of the river water current. The monitoring of the flood will undergo predictive analytics using prediction equation for statistical modeling algorithm to observe the behavior of the river and rainfall for possible flood risk.

\section{Related literature/ studies}

According to Blaikie et al. (2014), the past decade had been a very significant period in relation to flood around the world, for several reasons. Some of the most extensive, damaging and costly floods have occurred in developed, wealthy countries. Flooding in less developed countries (LDCs) has appeared to be increasingly frequent and serious. Such floods have become increasingly associated with climate change: the popular and media perception has been of an increased frequency of floods and storms supposedly resulting from global warming [4].

Pati et al. (2017) mentioned in their research "Flood Vulnerability of the Town of Tanay, Rizal, Philippines" that the social vulnerability of the flood-prone barangays in the town was also determined using proxy indices. The model successfully predicted the flood depths and delineated the spatial extent of flooding in the different barangays of the town. Barangay Tabing Ilog had the highest overall vulnerability index as the most vulnerable to flood and needs a comprehensive flood risk preparedness. This means that most of the people who lived near river needs a flood risk preparedness to become aware for a flash flood [5].

To solve the risk of a flash flood, another paper from Santillan et al. (2013) presented how geospatial technologies using Geographic Information System which can be used in near-real time monitoring and flood forecasting. They developed and parameterized a nearreal time flood extent monitoring numerical model for Marikina River, Philippines using 
River Analysis System (HEC RAS) program. They developed a forecasting system for Marikina River that provides water level forecasts for the next 48 hours. Forecasts are results of model simulation of basin hydrology as well as river and floodplain hydraulics, using recorded data of rainfall events 3 days ago to present time as primary input of the models [6].

Flash flood prediction is a good thing that every community must have especially in a riverbank. De Castro et al. (2013) proposed a paper to develop a technology on Flash Flood Warning System Using SMS with advanced warning information based on prediction algorithm regarding increasing water level and water speed. These two factors were considered as triggers to the flashflood, thus become components of the regression/ statistical modeling algorithm devised by the researchers. Based on the training data captured for seven days, the regression equation was developed while the actual/real time data were input to the regression model. Prediction of the current and forthcoming risk on flood is computed by the system based on the model and is sent through SMS to registered users for early warning purposes [7].

To provide accurate analysis to the data that will be gather for a possible flood, Kitagami et al. (2016) established an effective application of IoT (Internet of Things) for disaster prediction. Applications for flood disaster prediction, an early warning of the flash flood caused by locally heavy rain is required as well as a flood impact analysis based on water level and rainfall monitoring in the whole drainage basin. To evaluate the method, they developed a prototype system and conducted a field trial in Quang Nam Province, Vietnam. As the result of our evaluation, the proposed method can reduce the network load for flood monitoring, and can issue the flood warning at proper timing [8].

Some flood risk analysis uses a statistical modeling algorithm that plays an important role for the sensor networks. Likewise, the study of Basha et al. (2008) presented a sensor network with a statistical modeling algorithm for river flood prediction. It is based on a regression model that performs significantly better than current hydrology research versions at 1 hour predictions For prototyping and validation purposes, we tested this model using 7 years of data from the Blue River in Oklahoma [9].

Raspberry Pi is new in the Philippines when it comes to Alert System. In relation, Kayte et al. (2017) developed a project to monitor the water level in dam using the advanced concept of IOT employing Raspberry Pi sensor is placed in the dam to serve the same purpose automatically and forward the status to raspberry pi and upload status on web. By this project each and every variation of water level is informed to control room through internet and nearby people can be informed in time thus saving lots of lives avoiding the unpleasant scenarios [10].

To synthesize all the information, most flood prediction nowadays used microcontroller and sensor technology which monitor the river flash flood. Flood risk analytics provides accurate data for online flood forecasting. Recent Studies uses wireless sensor devices such as water level, water pressure and rainfall separately. Likewise, the current study aims organize and combine all the existing technology today using embedded system. Similarly, the study of Kate et al., the proposed study will apply the same technology. Live monitoring of the water pressure, water level and rainfall sensors as combined from the previous study of Basha et al. and De Castro et al. This study differs from the previous studies since web-based application provides data observation represented as chart with flood analytics for early prediction. For the data analysis, a statistical modeling algorithm for river flood prediction was used with the same algorithm based on the regression model.

\section{Methodology}


The researchers used the system development design for the study. System plan using system architecture was applied. Unit testing was conducted to validate the data coming from the system project as controlled by the microcontroller with sensors. After the data collection, these were analyzed by the system project using regression analysis under statistical modelling. All the data are interpreted by a web-based system using flood risk analytics and the result will be generated using the predictive analytics to calculate the flood history.

Under system development methodology, the researcher applied the waterfall of the system development life cycle. In requirements analysis, data requirements table, data gathering procedures, and hardware specification are used in the project. In system design, the use-case diagram, sequence diagram, system flow, and data flow diagram were used in the study. In implementation phase, functional testing was used for sensor modules. In integration and testing, all the logs from the sensor devices (rain gauge, water flow meter, water level) will be used as history logs with the help of statistical modelling algorithm for flood prediction. In deployment phase, the microcontroller and sensors were deployed in the river bank while the flood monitoring website are handled by the Disaster Management team.

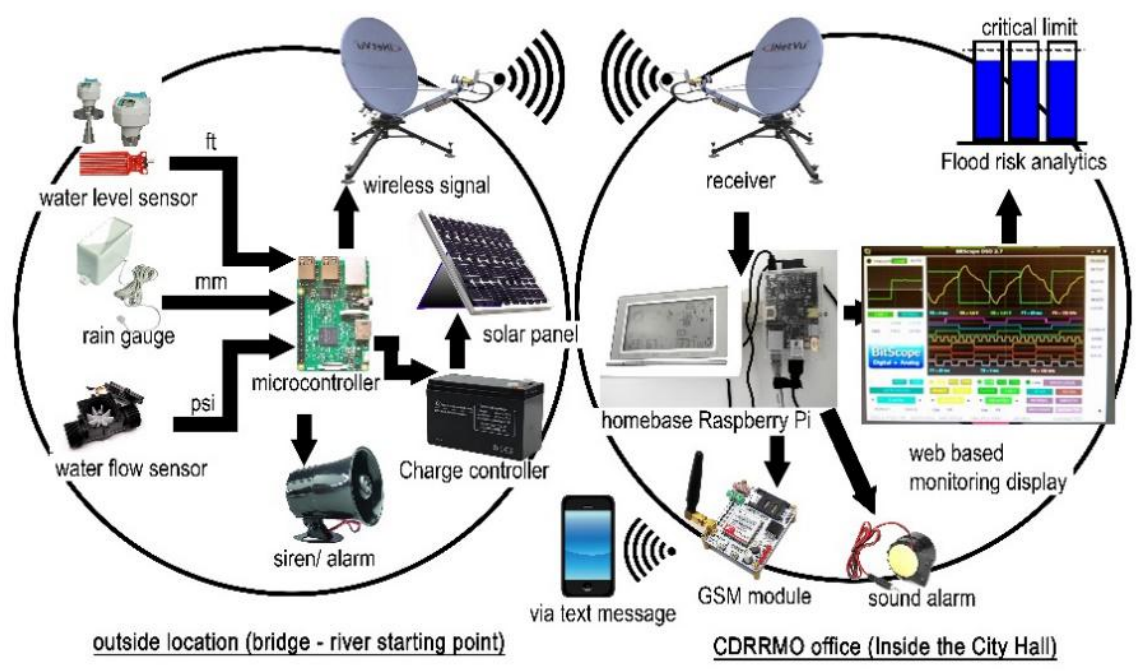

Fig. 1. Flood Monitoring System Architecture.

Figure 1 represents the prototype architecture design of the study. Sensors data logs will receive by the microcontroller and sends data wirelessly to another microcontroller to analyze data and responds if the data reaches the critical level and will be used as a sign for emergency response through alarm and SMS (short messaging service). 


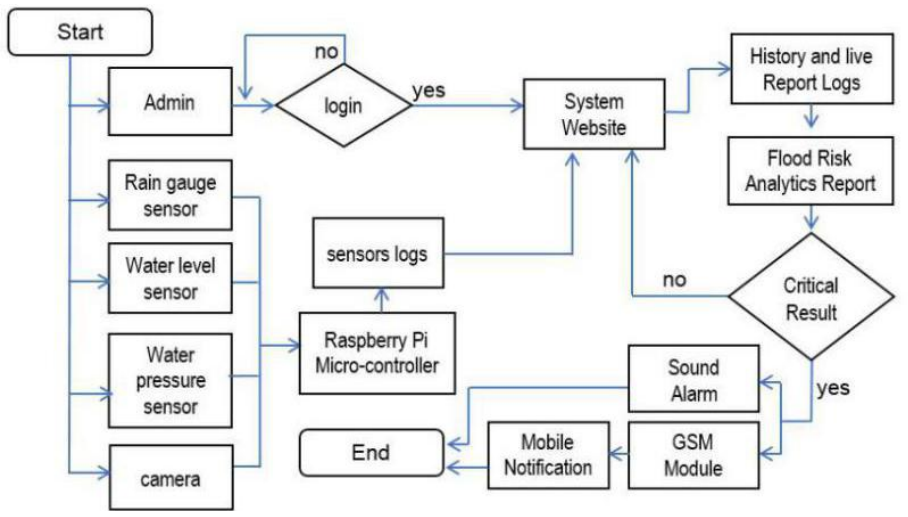

Fig. 2. Project System Flow.

Figure 2 represents the system flow of the Smart Disaster Prediction Application. Using the Raspberry Pi as the microcontroller, it can receive data from sensors and transfer sensor logs to the web and display history logs and live reports. The website will be able to display flood risk analytics report using flood prediction based on history logs. If the monitored data reaches the critical level, controlled SMS (short messaging service) notification and alarm will be triggered as early warning.

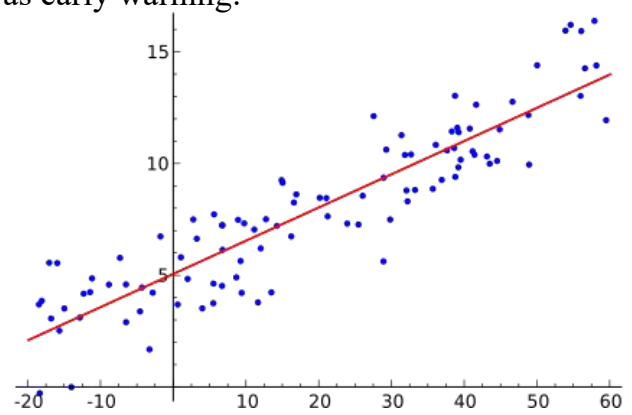

Fig. 3. Regression Model for Statistical Modeling Algorithm.

The researcher used the regression model using statistical modeling algorithm for the study. Likewise, the statistical modeling of Basha et al. (2008) for flood prediction as presented in Figure 3, regression analysis uses a set of statistical processes for estimating the relationships among variables. Regression models involve the following parameters and variables: The unknown parameters, denoted as $B$, which may represent a scalar or a vector, the independent variables, $\mathrm{X}$, and the dependent variable, $\mathrm{Y}$. A regression model relates $\mathrm{Y}$ to a function of $\mathrm{X}$ and $\beta$. $(\mathrm{Y}=f(\mathrm{X}, \beta))$ as sample result presented in figure 3.0.

To obtain the analytical model of the flow discharge, the regression model must be fit with an application. The obtained river flow regression models used in the real-life validation of the river flood prediction to provide results from the following parameters such as precipitation in millimeters for the rain, pounds PSI (per square inch) for the river water pressure and length in centimeters for the water level. The proposed methods are applicable for the solution of tasks.

Table 1. Multiple regression analysis - 7 days trial.

\begin{tabular}{|c|c|c|c|c|c|c|c|c|}
\hline \multicolumn{9}{|c|}{ Over-all Average } \\
\hline & Velocity & $=1$ & & & Level & $=2$ & & \\
\hline \multicolumn{9}{|c|}{ Deviation Average per day } \\
\hline Trials & $\mathrm{T} 1$ & $\mathrm{~T} 2$ & T3 & T4 & T5 & T6 & $\mathrm{T} 7$ & Avg. difference \\
\hline
\end{tabular}




\begin{tabular}{|l|l|l|l|l|l|l|l|l|}
\hline Velocity & 0 & 6.43 & 6.3 & -11.4 & -2.7 & 2.3 & 7.5 & 1.2 \\
\hline Level & 0 & 9.32 & 8.45 & -18.45 & -4.2 & 10.4 & 15.1 & 2.95 \\
\hline
\end{tabular}

The prediction model used by De Castro et al. was based on Multiple Regression Analysis is an example which was used in this study. In their study, the water level, and velocity was recorded during the 7-days observation based on the result above [11]. given:

The Prediction Model using the training data for 7 trials will be the input to the equation

$$
\begin{aligned}
& Y=a X+b \\
& Y=a+b 1 X 1+b 2 \times 2
\end{aligned}
$$

Equation (1) is a regression equation for the water level risk. The variable $\mathrm{Y}$ is a predicted model, while a is the dependent variable coefficient and b1 and b2 are the model factors computed based on the input values. While $\mathrm{x} 1$ is the water velocity and $\mathrm{x} 2$ is the water level. This will forecast the probability of a risk in the rise of water level. The model was computed with the input training data for seven days.

To compute for $\mathrm{a}$ and $\mathrm{b}$ for one variable, equations $3 \mathrm{a}$ and $3 \mathrm{~b}$ could be utilized. While for $\mathrm{b} 1$ and $\mathrm{b} 2$, the following equations are used:

$$
\begin{gathered}
\mathrm{a}=\overline{\mathrm{Y}}-\mathrm{b} \overline{\mathrm{X}} \\
b=\frac{\sum x y}{\sum x^{2}} \\
b_{1}=\frac{\left(\sum x_{2}^{2}\right)\left(\sum x_{1} y\right)-\left(\sum x_{1} x_{2}\right)\left(\sum x_{2} y\right)}{\left(\sum x_{1}^{2}\right)\left(\sum x_{2}^{2}\right)-\left(\sum x_{1} x_{2}\right)^{2}} \\
b_{2}=\frac{\left(\sum x_{1}^{2}\right)\left(\sum x_{2} y\right)-\left(\sum x_{1} x_{2}\right)\left(\sum x_{1} y\right)}{\left(\sum x_{1}^{2}\right)\left(\sum x_{2}^{2}\right)-\left(\sum x_{1} x_{2}\right)^{2}}
\end{gathered}
$$

In this case, b1 and b2 are the forecasted values for the water level, water pressure and rainfall that was used as well in this study for prediction. These are demonstrated in equations $3 \mathrm{c}$ and $3 \mathrm{~d}$. Once the values for $\mathrm{a}, \mathrm{b} 1$ and $\mathrm{b} 2$ are computed, these coefficients are entered into the multiple regression equation, which will result to the final model for predicting the water level, water pressure, rainfall and the relative risk.

The researchers applied the statistical modeling algorithm since the data can be observe time to time or day to day basis for river flood prediction.

Table 2. Data Requirements.

\begin{tabular}{|l|l|l|l|}
\hline \multicolumn{1}{|c|}{ Sensors } & \multicolumn{1}{c|}{ Data Used } & \multicolumn{1}{c|}{ Measurement } & \multicolumn{1}{c|}{ Units } \\
\hline Rain gauge & rainfall & Precipitation & mm (millimeters) \\
\hline Water flow sensor & water pressure & Pounds & PSI (per square inch) \\
\hline Water level sensor & water level & Length & $\mathrm{cm}$ (centimeter) \\
\hline
\end{tabular}

The Table 2 represents the data that was used generated from the sensor devices. For the rain gauge, rainfall was used measured in millimeters. For the water flow sensor, water pressure was measured in PSI. Sensor water level will measure in centimeter. Data from the main device will transfer through wireless transmission going to reports server to examine the collected data.

\section{Results and discussion}


The prototype testing was conducted to determine the accurate result generated by the rain gauge for the rainfall precipitation, water level sensor for the river water level and water pressure. The 7-day test was done on December 14 to December 20, 2017 during the tropical depression Urduja.

Table 3. Rainfall result - Precipitation.

\begin{tabular}{|c|c|c|c|c|c|c|c|}
\hline \multicolumn{8}{|c|}{ Rain Gauge - Rainfall - Precipitation (mm) } \\
\hline date/ & Dec. 14 & Dec. 15 & Dec. 16 & Dec. 17 & Dec. 18 & Dec. 19 & Dec. 20 \\
\hline & Thu.-D1 & Fri.-D2 & Sat.-D3 & Sun.-D4 & Mon.-D5 & Tue.-D6 & Wed.-D7 \\
\hline av & $\Rightarrow 11.44$ & 19.19 & 14.25 & 14.69 & $\sum 11.56$ & 2.63 & $\sqrt{12.94}$ \\
\hline all: & 50 & & $A$ & $\operatorname{infa}$ & $7 \mathrm{da}$ & 10.96 & mm \\
\hline
\end{tabular}

Computed Deviation per day (Based on Predicted model)

\begin{tabular}{|c|c|c|c|c|c|c|}
\hline Dec. 14 & Dec. 15 & Dec. 16 & Dec. 17 & Dec. 18 & Dec. 19 & Dec. 20 \\
\hline 4.29 & 5.43 & 4.43 & 5.29 & 4.00 & 1.00 & 1.57 \\
\hline \multicolumn{6}{|c|}{ avg: } & \multicolumn{4}{|c}{$\mathbf{3 1}$} \\
\hline
\end{tabular}

Table 3 represents the actual result of the rainfall measured in millimeter $(\mathrm{mm})$. Based on the 16 hours a day observation result within 7 days, the average rainfall recorded as $10.96 \mathrm{~mm}$ far from $50 \mathrm{~mm}$ as the critical rainfall in the Philippines. Based on the final prediction, the computed deviation average was 3.71 while the level of risk evaluated as "average".

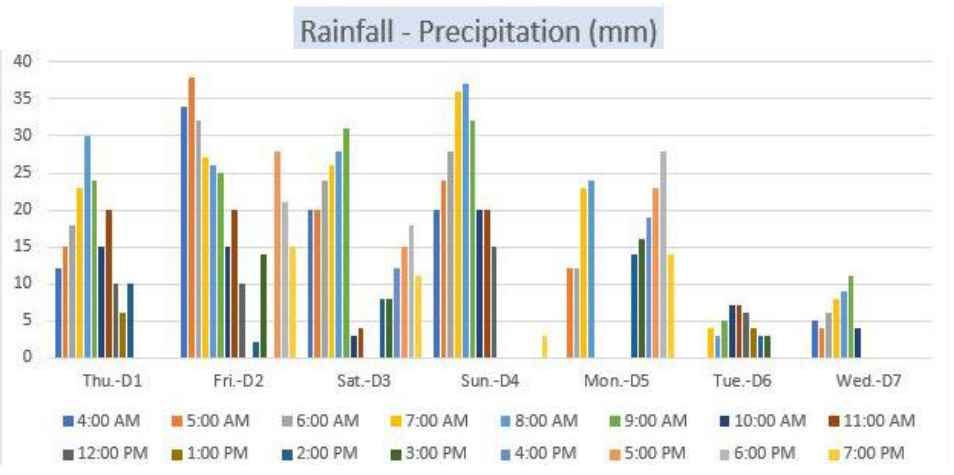

Fig. 4. Rainfall monitoring chart.

Figure 4 represents the monitoring chart from the web-based project displaying the 7 days (per hour) monitoring of the rainfall precipitation wherein day 2- Thursday had the highest rainfall average $19.19 \mathrm{~mm}$.

Table 4. Water pressure measured in pound PSI.

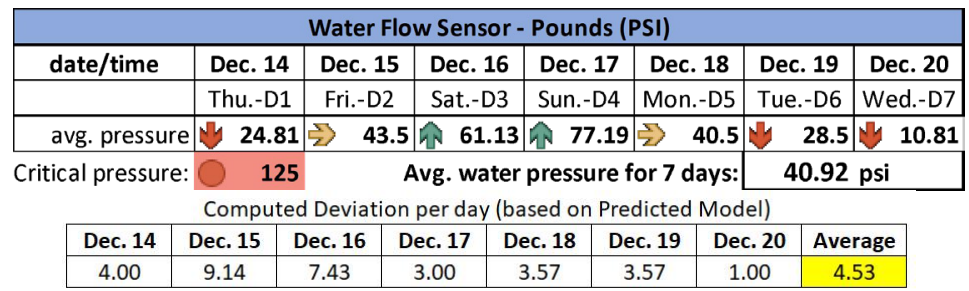

Table 4 represents the actual result of the water pressure measured in pounds PSI. Based on the 16 hours a day observation result within 7 days, the average pressure computation resulted to 40.92 psi far from 125 psi as the critical water pressure of the river. As final prediction, the computed deviation average was 4.53 while the level of risk evaluated as "average". 


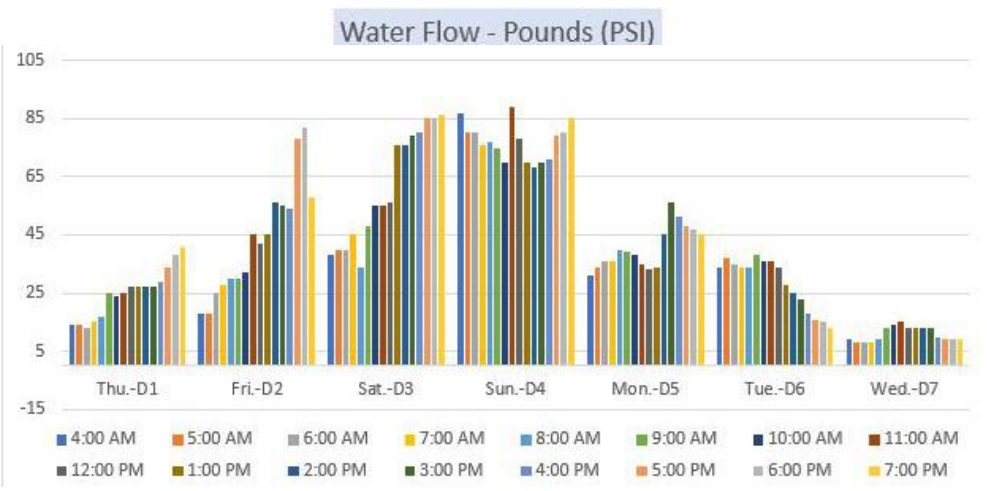

Fig. 5. Water flow monitoring chart.

Figure 5 represents the monitoring chart from the web-based project displaying the 7 days (per hour) monitoring of the water flow pressure wherein day 4 had the highest average result of 77.19 psi.

Table 5. Water level measured in cm length.

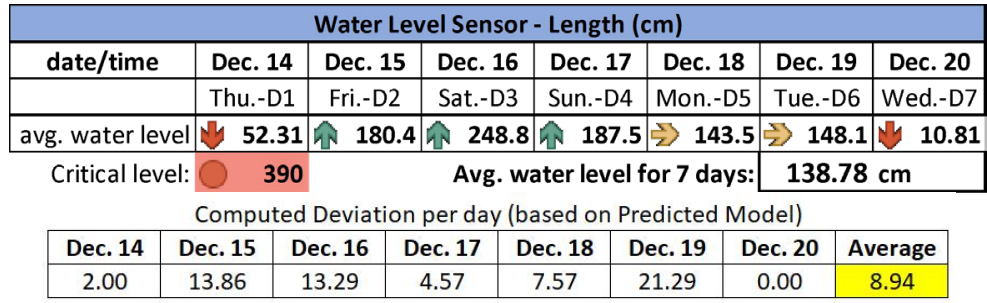

Table 5 represents the actual result of the water level measured in centimeter $(\mathrm{cm})$. Based on the 16 hours a day observation result within 7 days, the average water level resulted to $137.78 \mathrm{~cm}$ far from $390 \mathrm{~cm}$ as the critical water level. Based on the final prediction, the computed deviation average was 8.94 while the level of risk evaluated as "average".

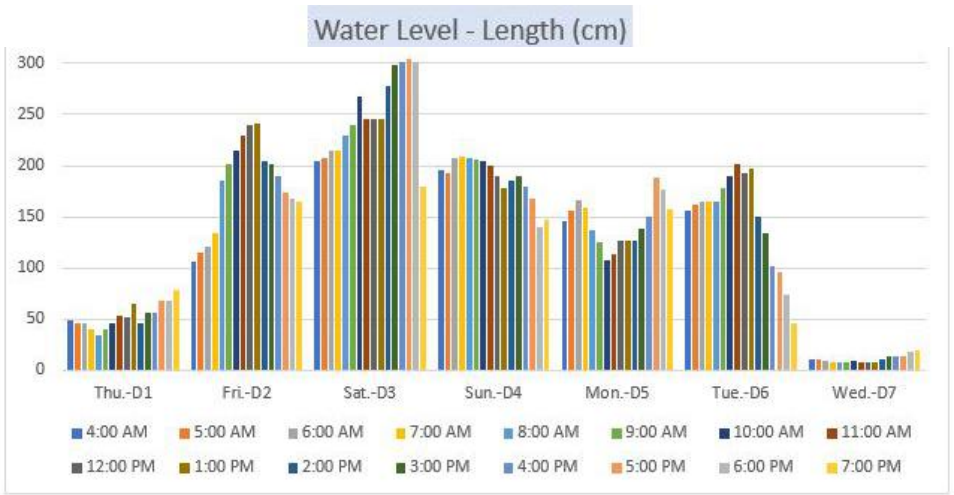

Fig. 6. Water level monitoring chart.

Figure 6 represents the monitoring chart from the web-based project displaying the 7 days (per hour) monitoring the water level wherein day 3 had the highest average of 248.8 $\mathrm{cm}$ water level. 
Compared to the result of Chang et al., the total number of typhoon or heavy rainfall events in Taiwan is 132, which include 8640 hourly data sets. The observed water level and one to three steps ahead water level predictions of Shihmen reservoir in testing phase was used to provide accurate and reliable water level prediction. As the average result, it was observed that an average of $244 \mathrm{~m}$ from $238 \mathrm{~m}$ including the 3 hour-step prediction [12].

Likewise, the paper from De Castro et al. uses water level and velocity from the 7 days' trial test of their flood warning system. The same with the current study, their data results recorded per hour with computed average velocity of $10.97 \mathrm{~m}^{3} / \mathrm{s}$ (cubic metres per second) and water level of $17.28 \mathrm{CI}$ (cubic inch). The overall average of 7 days' observation resulted to $15.04 \mathrm{~m}^{3} / \mathrm{s}$ velocity and $17.28 \mathrm{CI}$ water level. Based on the final Prediction using Prediction model. The highest deviation calculated is 3.57 and the lowest is -3.44 .

\section{Conclusions}

In summary, using the prototype of the Smart Disaster Prediction Application, the three important sensor devices attached to microcontroller accurately responds after calibration to measure the rainfall precipitation measured in millimeter, water pressure measured in pound PSI and water level measured in length centimeter.

Rainfall resulted to $10.96 \mathrm{~mm}$ since on that particular day remarked as moderate rain since the storm surge did not land the Laguna area directly on that test date. The effect of precipitation caused the water level in the river to rise from its lowest 40 centimeters to $138.78 \mathrm{~cm}$ as the average water level. The water pressure responds on the increased of the water level with an average of 40.92 pounds' psi. 54.7 psi of water flows in 12 inches per second as resulted to slow moving of the water pressure far from the critical water level of 125 psi. The three (3) results gathered from the sensor devices was observed during 7 days. The observation results reflected that day 3 and day 4 had the highest amount of average rainfall, water pressure and water level that resulted to increase of water level in the river after 2 days of tropical depression.

This prototype test during the tropical depression Urduja in the Philippines had shown the accuracy of the prototype in revealing the information regarding the rainfall, water pressure and water level. The result given by the prototype device shows that it can be used by the City Disaster Risk and Reduction Management Office for disaster prediction.

\section{References}

1. Tingsanchali, T. (2012). Urban flood disaster management. Procedia engineering, 2537.

2. Lagmay, A. M. F. A., Racoma, B. A., Aracan, K. A., Alconis-Ayco, J., \& Saddi, I. L. (2017). Disseminating near-real-time hazards information and flood maps in the Philippines through Web-GIS. J. of Environmental Sciences.

3. Krzhizhanovskaya, V. V., Shirshov, G. S., Melnikova, N. B., Belleman, R. G., Rusadi, F. I., Broekhuijsen, B. J., ... \& Pyayt, A. L. (2011). Flood early warning system: design, implementation and computational modules. Procedia Computer Science, 4, 106-15.

4. Blaikie, P., Cannon, T., Davis, I., \& Wisner, B. (2014). At risk: natural hazards, people's vulnerability and disasters. Routledge.

5. Pati, R. C., \& Cruz, A. P. (2017). Flood Vulnerability of the Town of Tanay, Rizal, Philippines. Philippine J. of Science, 146(2), 117-27.

6. Santillan, J. R., Ramos, R. V., Recamadas, S., David, G., Paringit, E. C., Española, N. C., \& Alconis, J. (2013). Use of geospatial technologies and numerical modeling to 
monitor and forecast flooding along Marikina River, Philippines. Proceedings of the 12th SEASC: Geospatial Cooperation Towards a Sustainable Future, 25.

7. Joel T. de Castro, Gabriel M. Salistre, Jr, Young-Cheol Byun and Bobby D. Gerardo, Member, IAENG (October, 2013)" Flash Flood Prediction Model based on Multiple Regression Analysis for Decision Support System "Proceedings of the World Congress on Engineering and Computer Science 2013 Vol II WCECS 2013

8. Kitagami, S., Thanh, V. T., Bac, D. H., Urano, Y., Miyanishi, Y., \& Shiratori, N. (2016). Proposal of a Distributed Cooperative IoT System for Flood Disaster Prevention. Int. J. of Internet of Things, 5(1), 9-16.

9. Basha, E. A., Ravela, S., \& Rus, D. (2008, November). Model-based monitoring for early warning flood detection. In Proceedings of the 6th ACM conference on Embedded network sensor systems (pp. 295-308). ACM.

10. Kayte (2017), S. D., Jamodkar, S., \& Raut, M. Raspberry Pi Based Automatic Dam Monitoring and Alert System.

11. de Castro, J., Salistre Jr, G., Byun, Y., \& Gerardo, B. D. (2013). Flash Flood Prediction Model based on Multiple Regression Analysis for Decision Support System. Vol. 2

12. Chang, F. J., \& Chang, Y. T. (2006). Adaptive neuro-fuzzy inference system for prediction of water level in reservoir. Advances in water resources, 29(1), 1-10. 